\title{
Licenciaturas EM Ciências da Natureza do Instituto Federal de Educação, CiênCIa E TECNOLOGIA DE RONDÔNIA (IFRO): O SABER O QUE ENSINAR
}

\author{
NATURAL SCIENCES UNDERGRADUATE COURSES OF THE FEDERAL \\ INSTITUTE OF EDUCATION, SCIENCE AND TECHNOLOGY OF RONDÔNIA \\ (IFRO): KNOWING WHAT TO TEACH
}

DOI: http://dx.doi.org/10.23926/RPD.2526-2149.2020.v5.n1.p249-270.id580

\section{Maranei Rohers \\ Penha \\ Doutora em Educação \\ Ciências e Matemática \\ (REAMEC/UFMT) \\ Professora no Instituto \\ Federal de Rondônia (IFRO) \\ maranei.rohers@ifro.edu.br}

\section{Marta Maria Pontin \\ Darsie}

Doutora em Educação (USP)

Professora da Universidade

Federal de Mato Grosso

(UFMT)

Professora da Rede

Amazônica de Educação em

Ciências e Matemática

(REAMEC)

marponda@uol.com.br
Resumo: Este artigo resulta de uma pesquisa realizada nas licenciaturas em Ciências da Natureza do Instituto Federal de Educação, Ciência e Tecnologia de Rondônia, por meio de análise documental e questionário misto, e integrou parte de uma pesquisa de doutorado, que objetivou compreender os processos de implantação de licenciaturas no IFRO e a formação inicial de professores das referidas licenciaturas. A análise de quatro Projetos Pedagógicos de Cursos, vigentes entre 2010/1 e 2015/2, evidenciou significativa diferença quantitativa de oferta de disciplinas relacionada ao saber o que ensinar e ausência de disciplinas vinculadas a saberes regionais. A pesquisa também demonstrou que 72,7\% dos Docentes Formadores afirmaram que as licenciaturas em Ciências Biológicas, Física e Química garantem a aprendizagem do saber o que ensinar; contudo, apontaram a necessidade de mais discussões e ações coletivas. Todos os Professores Egressos declararam que o saber o que ensinar foi assegurado durante seus processos de formação inicial.

Palavras-chave: Formação inicial em Ciências da Natureza; IFRO; Saber o que ensinar.

Abstract: This article is the result of research carried out in undergraduate courses in Natural Sciences at the Federal Institute of Education, Science and Technology of Rondônia, through document analysis and mixed questionnaire, and it was part of a doctoral research, which aimed to understand the processes implementation of undergraduate courses at IFRO and the initial training of teachers of those undergraduate courses. The analysis of four Pedagogical Course Projects, in force between 2010/1 and 2015/2, showed a significant quantitative difference in the supply of disciplines related to knowing what to teach and the absence of disciplines linked to regional knowledge. The survey also showed that $72.7 \%$ of the Teaching Professors stated that the degrees in Biological Sciences, Physics and Chemistry guarantee the learning of the knowledge to teach; however, they pointed out the need for more discussions and collective actions. All graduating professors stated that to know what to teach was ensured during their initial training processes.

Keywords: Initial training in Natural Sciences; IFRO; Know what to teach. 


\section{INTRODUÇÃO}

Esta investigação teve como foco os cursos de licenciatura em Ciências da Natureza de quatro dos nove campi do Instituto Federal de Educação, Ciência e Tecnologia de Rondônia (IFRO) - Colorado do Oeste, Ji-Paraná, Ariquemes e Porto Velho Calama.? Objetivamos compreender os processos de implantação de licenciaturas no IFRO e a formação inicial de professores de Ciências da Natureza. O trabalho versa especificamente sobre o saber o que ensinar. Para Gatti e Nunes (2009), tal saber se constitui como um dos conhecimentos específicos das disciplinas relacionadas a conteúdos destinados à Educação Básica nos Projetos Pedagógicos dos Cursos (PPC) de Ciências Biológicas, Química e Física. Nesta pesquisa, investigou-se a visão dos Docentes Formadores (DFs) que lecionam nesses de licenciatura, bem como a dos Professores Egressos (PEs) que lecionam na Educação Básica e que fizeram sua graduação entre 2010/1 e 2015/2. Esse período coincidiu com o da formação da primeira turma de licenciados de cada um dos cursos dos referidos campi.

A pesquisa foi desenvolvida a partir de uma abordagem qualitativa, com base na análise documental dos PPCs de Ciências Biológicas, Química e Física dos quatro campi considerados e na aplicação de um questionário misto a trinta e três (33) DFs e cinco (05) PEs. A partir desta introdução, o artigo está organizado em outras três seções, para além das considerações finais. A primeira seção versa sobre o referencial teórico a respeito do saber o que ensinar, especificamente no contexto das licenciaturas em Ciências da Natureza. A segunda apresenta a metodologia e nela registramos a trajetória percorrida no desenvolvimento desta pesquisa. Em seguida, a terceira expõe os resultados embasado em três visões: 1) o saber o que ensinar nos PPCs de licenciaturas em Ciências da Natureza do IFRO; 2) a visão dos DFs a respeito do saber o que ensinar nas licenciaturas em Ciências da Natureza do IFRO e 3) a visão dos PEs a respeito do saber o que ensinar nas licenciaturas em Ciências da Natureza do IFRO.

\section{REFERENCIAL TEÓRICO}

Como reflexo da preocupação com os saberes próprios da docência, estes têm sido debatidos intensamente no desenvolvimento dos cursos de licenciatura como forma de garantilos no processo de formação inicial dos futuros professores.

Discutir e tentar compreender o contexto da formação de professores decorre inclusive da nossa própria vivência na condição de alunos, da relação que a sociedade tem com a educação e das experiências que vivenciamos no universo escolar no decorrer da vida (NIZA, 2012). Neste contexto, o saber o que ensinar, tópico intrínseco ao campo da formação de 
professores, vem sendo tratado por autores que, direta ou indiretamente, têm colaborado para a propositura de legislações, normas e diretrizes que dispõem sobre esse assunto nas licenciaturas.

Entre as legislações que versam sobre o saber o que ensinar, está a Resolução CNE/CP n. ${ }^{\circ}$ 2/2015. Em seu art. 12, ela dispõe, por meio dos denominados "núcleos de formação", três grupos orientadores da elaboração e desenvolvimento dos saberes veiculados nos cursos de licenciaturas. São eles:

I. Núcleo de estudos de formação geral, das áreas específicas e interdisciplinares, e do campo educacional, seus fundamentos e metodologias, e das diversas realidades educacionais; II. Núcleo de aprofundamento e diversificação de estudos das áreas de atuação profissional, incluindo os conteúdos específicos e pedagógicos e a pesquisa priorizadas pelo projeto pedagógico das instituições, em sintonia com os sistemas de ensino; e III. Núcleo de estudos integradores para enriquecimento curricular (BRASIL, 2015, p. 8-11).

Entre os autores que têm pesquisado o saber o que ensinar nos cursos de formação inicial de professores estão Shulman (1986), García (1995), Gauthier et al. (1998), Jiménez e Bravo (2000), Tardif (2003), Bolzan (2006) e Barbosa (2012). Apesar de apresentarem posições e conceitos distintos, todos esses autores ponderam a respeito da influência que esses núcleos têm na formação docente. Por exemplo, em relação ao saber o que ensinar, Shulman (1986) discorre sobre o conhecimento do conteúdo específico a ser ensinado. $\mathrm{O}$ autor considera que tanto a quantidade quanto a maneira de organizar o conteúdo depende da própria sistematização intelectual do docente. Esse profissional deve estabelecer relações entre os assuntos da sua matéria com os assuntos dos demais campos do conhecimento - a interdisciplinaridade é, de fato, um aspecto importante da tarefa de ensinar. Segundo Shulman, cada campo (matéria) contém uma forma própria de discutir a estrutura de conhecimento, para se apropriar dos conteúdos e reconhecer os acontecimentos. Isto pode se dar por meio de ocorrências, conceitos, processos e metodologias de certa área particular do conhecimento ou mesmo por meio de áreas afins.

Já para García (1995), o saber o que ensinar nas licenciaturas está relacionado àquilo que versa sobre uma área específica de cada disciplina, o que perpassa pelo conteúdo em si - o que se vai ensinar é o que tem sido comumente denominado no meio educacional como "área dura". Para o autor, ensinar o conteúdo de uma determinada disciplina ou área implica conhecer a estrutura, pois isso possibilitará ao professor representar, de forma correta e segura, o conhecimento intrínseco de uma área específica, como por exemplo, Ciências, Biologia, Física, Química, etc. sem perder de vista a oportunidade de promover uma integração entre os conteúdos (GARCIA, 1995). 
Gauthier et al. (1998) e Tardif (2003), ao tratarem do saber o que ensinar, abordam os chamados "saberes disciplinares", que se originam das várias áreas do conhecimento e que, na nossa sociedade, podem ser encontrados nas Instituições de Ensino Superior, organizados por meio de disciplinas (Biologia, Física, Geografia, Matemática, Química etc.). Para Jiménez e Bravo (2000), é preciso ter cuidado quanto ao ensino do saber o que ensinar, pois, a partir do momento em que o conteúdo a respeito do ensinar é trabalhado de maneira apressada, os licenciandos, quando professores, buscarão opiniões alternativas a respeito de conceitos científicos. Sendo assim, eles poderão apresentar limitações ao realizar transformações didáticas, evitando ensinar os assuntos que não dominam e apresentando dúvidas e falta de confiança nas abordagens das Ciências. Tais professores baseiam-se predominantemente no livro didático, tanto no que se refere ao instruir como no que diz respeito ao avaliar, e privilegiam a memorização do conhecimento, o que pode acabar por desencadear nos alunos uma repulsa às disciplinas científicas.

Bolzan (2006, p. 357-358), ao discutir o saber o que ensinar, define esse tópico como sendo o conjunto de

[...] conhecimentos sobre a matéria a ser ensinada pelo professor. Constitui-se por elementos conceituais e organizacionais dos conteúdos próprios da disciplina, envolvendo ideias, informações, definições, convenções e tópicos gerais, bem como sua estrutura organizacional. Implica no conhecimento das tendências e perspectivas de seu campo específico, incluindo as diferentes interpretações de um mesmo fenômeno e suas relações pelo professor.

Conforme afirma o autor, é necessário que o professor, além do conhecimento específico, inerente à disciplina, detenha outros conhecimentos e mantenha-se atualizado em relação aos movimentos de mudanças em sua área. Isto deve se estender, inclusive, às distintas análises e críticas sobre um fenômeno ou evento, para que o próprio docente estabeleça uma forma própria de abordar os conteúdos com segurança. Já Barbosa (2012, p. 66), defende que o curso de licenciatura precisa formar bem o profissional que irá "atuar na escola de Educação Básica, um educador em Ciências Naturais, que compreende o conhecimento escolar organizado em grandes áreas do conhecimento, como propõem as diretrizes curriculares para a Educação Básica”.

Nesse sentido, é importante não perder de vista que, na formação em licenciatura para as disciplinas de Ciências, Biologia, Física e Química, para atuar na Educação Básica, no nível do Ensino Fundamental (do $6^{\circ}$ ao $9^{\circ}$ ano) e no Ensino Médio $\left(1^{\circ}, 2^{\circ}\right.$ e $3^{\circ}$ anos), as Instituições de Ensino Superior precisam assegurar a apropriação e a reorganização dos conhecimentos previstos nas Diretrizes Curriculares. Deste modo, tanto a origem quanto a diversidade dos 
conhecimentos mobilizados pelos DFs sofrem uma reestruturação no exercício da sua prática profissional, com o objetivo de que se adaptem e se transformem para e pelo futuro educador (BORGES, 2004).

Por outro lado, o Conselho Nacional de Educação (CNE)/Conselho Pleno (BRASIL, 2015, p. 8), no art. $8^{\circ}$, inciso IV da Resolução n. ${ }^{\circ}$ 2/2015, afirma que, além de ter propriedade nos conhecimentos de cunho específico, o licenciado precisa dominar "as abordagens teóricometodológicas do seu ensino, de forma interdisciplinar e adequada às diferentes fases do desenvolvimento humano". Nesta mesma linha argumentativa, ao tratar sobre a aprendizagem de conteúdos na licenciatura, Mizukami et al. (2002, p. 19) registram que a graduação é o "momento por excelência da formação profissional, no qual se dá a apropriação do conhecimento profissional a ser aplicado à futura atuação". Trata-se de um momento sem dúvida necessário, mas a aprendizagem por parte do professor não se limita a isso.

Nessa perspectiva, os pareceres do CNE/Câmara de Educação Superior (CES) n. ${ }^{\circ}$ 1.301/2001 (Ciências Biológicas) e CNE/CES n. ${ }^{\circ}$ 1.303/2001 (Química) registram que

Para a licenciatura [...] [em Ciências Biológicas e Química] serão incluídos, no conjunto dos conteúdos profissionais, os conteúdos da Educação Básica, consideradas as Diretrizes curriculares Nacionais para a formação de professores em nível superior, bem como as Diretrizes Nacionais para a Educação Básica e para o Ensino Médio. (BRASIL, 2001c p. 6; BRASIL, 2001b, p. 9;).

O Parecer CNE/CES n. ${ }^{\circ}$ 1.304/2001 (Física), por sua vez, que o físico, independentemente do seu enfoque de trabalho, fundamente sua profissão

apoiado em conhecimentos sólidos e atualizados em Física, capaz de abordar e tratar problemas novos e tradicionais e deve estar sempre preocupado em buscar novas formas do saber e do fazer científico ou tecnológico. Em todas as suas atividades a atitude de investigação deve estar sempre presente, embora associada a diferentes formas e objetivos de trabalho (BRASIL, 2001a, p. 3).

Em se tratando de conhecimentos a serem assimilados pelos licenciandos, é necessário considerar, nos cursos de formação inicial de professores, especialmente a partir da década de 1990, os documentos legais oriundos de políticas públicas e de marcos legais, tais como a Lei de Diretrizes e Bases da Educação (Lei n. ${ }^{0}$ 9.394/1996), os decretos, as resoluções e os Parâmetros Curriculares Nacionais, entre outros.

Neste aspecto, cabe registrar que a cada época, a formação inicial de professores foi se desenvolvendo e respondendo às necessidades da sociedade e, no momento, busca-se uma formação docente que prime pelo ensino crítico e que conduza à cidadania. Para Buchmann (1984, p. 37), “conhecer algo nos permite ensiná-lo; e conhecer um conteúdo com profundidade significa estar mentalmente organizado e bem preparado para ensiná-lo de uma forma geral". 
Portanto, em se tratando de ensino-aprendizagem, deve-se conhecer bem a matéria, mas esta somente apresentará sentido em conjunto com outros conhecimentos vinculados à docência ou seja, o ensino precisa de domínio técnico, mas não apenas disso.

Nesse conjunto de conhecimentos relacionados à docência, compete destacar a importância de uma formação fundamentada no desenvolvimento de um futuro professor praticum reflexivo (SCHÖN, 1983). Sendo assim, oportunizar a produção e a construção de um saber para que esse profissional seja capaz "de intervir no mundo, de comparar, de ajuizar, de decidir, de romper, de escolher [...]" (FREIRE, 1996, p. 22), isto é, o objetivo é formar um professor comprometido com as demandas da sociedade e das pessoas que se encontram em condições sociais com maior vulnerabilidade.

\section{Metodologia}

Neste artigo, pretendemos compreender de que forma os cursos de licenciatura em Ciências da Natureza do IFRO contemplam o saber o que ensinar. Sendo assim, procuramos, na pesquisa qualitativa, os fundamentos indispensáveis para o desenvolvimento deste estudo, considerando que, nessa abordagem, o pesquisador " $[. .$.$] trabalha com o universo de$ significados, motivos, aspirações, crenças, valores e atitudes, o que corresponde a um espaço mais profundo das relações, dos processos e dos fenômenos [...]” (MINAYO, 2001, p. 22).

Esta pesquisa, seguindo também uma abordagem documental, como instrumento para a produção de dados deu-se em razão de que

[...] o documento escrito constitui uma fonte extremamente preciosa para todo pesquisador nas Ciências Sociais. Ele é, evidentemente, insubstituível em qualquer reconstituição referente a um passado relativamente distante, pois não é raro que ele represente a quase totalidade dos vestígios da atividade humana em determinadas épocas. Além disso, muito frequentemente, ele permanece como o único testemunho de atividades particulares ocorridas num passado recente (CELLARD, 2008, p. 295).

A investigação de cunho qualitativo foi desenvolvida com a participação de trinta e três (33) DFs e cinco (05) PEs dos cursos de Licenciatura em Ciências Biológicas (campi de Colorado do Oeste e Ariquemes), em Química (campus de Ji-Paraná) e em Física (campus de Porto Velho Calama) do IFRO. Para compreendermos de que forma os cursos investigados contemplam o saber o que ensinar e obtermos respostas à questão "como os cursos de licenciatura em Ciências da Natureza do IFRO garantem o saber o que ensinar?", analisamos os PPCs dos referidos cursos, verificando as disciplinas destinadas aos estudos dos conteúdos denominados, geralmente, como específicos, de referência, da matéria, da área ou da disciplina. 
Assim, em nosso estudo, a pesquisa documental foi indispensável para obtermos os dados e compreendermos como os cursos de licenciaturas em Ciências da Natureza sistematizam as disciplinas que tratam dos saberes pertinentes ao que ensinar durante a formação inicial dos futuros professores. A opção pela aplicação de questionários mistos, aplicados aos DFs e aos PEs, teve como fundamento os estudos de Selltiz (2007). De acordo com o autor Selltiz (2007, p. 273), o sujeito investigado manifesta o que "sabe, crê ou espera, sente ou deseja, pretende fazer, faz ou fez, bem como a respeito de suas explicações ou razões para quaisquer das coisas precedentes”. Essa é a razão pela qual, neste estudo, a aplicação dos questionários constituiu etapa relevante.

Após a leitura dos PPCs e a aplicação dos questionários aos DFs e PEs, definimos quatro eixos de análise para os dados produzidos. São eles: eixo I: licenciaturas em Ciências da Natureza do IFRO; eixo II: saber o que e como ensinar; eixo III: teoria e prática e eixo IV: a pesquisa na formação docente nas licenciaturas do IFRO. Tais eixos possibilitaram inferências e interpretações e o estabelecimento de inter-relações com a literatura da área de formação de professores, dirimindo, concomitantemente, as inseguranças e fortalecendo o direcionamento argumentativo da leitura dos dados produzidos.

Neste artigo, limitamo-nos a apresentar os resultados relativos ao eixo II - o saber o que ensinar nos PPCs de licenciatura em Ciências da Natureza. Nesse eixo, sistematizamos e analisamos as disciplinas que, contidas nos projetos, tratam dos conteúdos específicos dos cursos investigados. Consideramos também os pontos de vista sobre o saber o que ensinar dos DFs e PEs. Conforme já adiantado, este artigo é um recorte da tese de doutorado intitulada A implantação e implementação de Licenciaturas de Ciências da Natureza no Instituto Federal de Educação, Ciência e Tecnologia de Rondônia - IFRO (2018).

\section{Resultados}

Os resultados de pesquisa serão apresentados em três seções. A primeira versa sobre os PPCs analisados, a segunda apresenta a visão dos DFs a respeito do saber o que ensinar, estando subdividida em quatro subseções, e a terceira expõe a visão dos PEs acerca do saber o que ensinar. Todas as seções dizem respeito aos cursos de licenciatura em Ciências da Natureza do IFRO, já indicados anteriormente.

\subsection{O SABER O QUE ENSINAR NOS PPCS DE liCENCIATURA EM CiÊNCIAS da NATUREza}

Uma das maneiras de entender o que vem sendo desenvolvido na Educação Básica é voltar a nossa atenção para os cursos de formação inicial de professores, mais especificamente 
para as suas matrizes curriculares. Assim, com o intuito de compreender de que maneira os cursos de licenciatura em Ciências da Natureza do IFRO contemplam o saber o que ensinar, analisamos o currículo proposto nos PPCs dos cursos considerados, à luz das diretrizes curriculares nacionais para as licenciaturas em Ciências Biológicas, Química e Física. Considerado o período de 2010/1 a 2015/2, identificamos de dezessete (17) a trinta e uma (31) disciplinas com ênfase no saber o que ensinar, conforme apresentadas a seguir.

Licenciatura em Ciências Biológicas: 1. Biologia Geral, 2. Sistemática e Taxonomia Filogenética, 3. Filosofia e História da Biologia, 4. Química Orgânica, 5. Biologia Celular, 6. Ecologia de Populações, 7. Histologia, 8. Bioquímica, 9. Zoologia dos Invertebrados I, 10. Ecologia de Comunidades e Ecossistemas, 11. Bioestatística, 12. Embriologia, 13. Genética Básica, 14. Anatomia e Morfologia Vegetal, 15. Zoologia dos Invertebrados II, 16. Biofísica, 17. Genética de Populações, 18. Fisiologia Vegetal, 19. Zoologia de Vertebrados I, 20. Zoologia de Vertebrados II, 21. Microbiologia, 22. Biologia e Sistemática Vegetal I, 23. Evolução, 24. Geologia, 25. Parasitologia, 26. Biologia e Sistemática Vegetal II, 27. Bioética, 28. Anatomia e Fisiologia Comparada dos Animais, 29. Paleontologia, 30. Anatomia e Fisiologia Humana, 31. Imunologia (1.481 horas) (IFRO, 2012b; 2012c, p. 24-25).

Licenciatura em Química: 1. Química Geral e Experimental I, 2. História da Química, 3. Química Orgânica I, 4. Química Geral e Experimental II, 5.Química Orgânica II, 6. Química Geral e Experimental III, 7. Química Orgânica III, 8. Química Inorgânica I, 9. Química Analítica Qualitativa, 10. Físico-Química I, 11. Química Inorgânica II, 12. Química Analítica Quantitativa, 13. Físico-Química II, 14. Química Ambiental, 15. Química Inorgânica III, 16. Química Instrumental, 17 Instrumentação para Uso de Laboratório no Ensino de Química. (1.260 horas) (IFRO, 2009, p. 15-16).

Licenciatura em Física: 1. Introdução a Física, 2. Física I, 3. Energia e Meio Ambiente, 4. Laboratório de Física I, 5. Física II, 6. Laboratório de Física II, 7. Física III, 8. Ética na Física, 9. Física IV, 10. Laboratório de Física III, 11. Mecânica Clássica, 12. Laboratório de Física IV, 13. Eletromagnetismo Clássico, 14. Estrutura da Matéria, 15. Termodinâmica, 16. Mecânica Quântica, 17. Tópicos de Astronomia, Física Estatística (1.400 horas) (IFRO, 2012a, p. 23-24).

Nos PPCs de licenciatura em Ciências da Natureza do IFRO, as disciplinas estão dispostas na matriz curricular por meio dos núcleos básicos, pedagógicos, específicos e complementares. Essa forma de apresentação atendeu às legislações em vigor e ao estabelecido nas contribuições para o processo de construção dos cursos de licenciatura do IFRO, os quais devem ter o desenho curricular de núcleo comum, núcleo específico, núcleo complementar e prática pedagógica.

Entretanto, analisando o rol de disciplinas propostas nesses PPCs, a disposição delas remete a algo fechado, diferente de uma proposição por componentes curriculares, conforme disposto na Resolução CNE/CP n. ${ }^{\circ}$ 1/2002 (BRASIL, 2002a), que foi mantida na CNE/CP n. ${ }^{\circ}$ 2/2015 (BRASIL, 2015), mais especificamente no que concerne à estrutura e ao currículo da formação inicial de professores para a Educação Básica em nível superior (art. 13). Essa resolução define uma organização para os cursos de licenciatura a partir de "áreas 
especializadas, por componente curricular ou por campo de conhecimento e/ou interdisciplinar [...]” (BRASIL, 2015, p. 11).

Anastasiou (2007, p. 56) compreende a matriz curricular como uma "soma das partes", ao passo que afirma que a matriz curricular se estabelece na "articulação das antigas disciplinas em componentes curriculares, áreas ou módulos, em torno de eixos [...]”. Com relação ao saber o que ensinar, também constatamos a escassez de disciplinas que tenham um cunho inovador ou, ainda, que possibilitem o conhecimento da região onde os cursos estão instituídos. Caso isso fosse contemplado, haveria um fortalecimento da relação do grupo de DFs com a região, com a possibilidade de uma reflexão que levasse em conta o contexto da localidade, o que diversificaria e constituiria um diferencial dos cursos de Ciências da Natureza do IFRO.

Nessa perspectiva, há que se pensar em um entendimento de formação inicial de professores na qual o conhecimento se efetive sob o aspecto da interdisciplinaridade. De acordo com a proposta de Japiassú (1976, p. 74), esta é caracterizada pela "intensidade das trocas entre especialistas e pelo grau de interação real das disciplinas, no interior de um projeto específico de pesquisa". Para tanto, conforme afirma Fazenda (2017, p. 31), é necessária "uma mudança de atitude perante o problema do conhecimento, da substituição de uma concepção fragmentária pela unitária do ser humano".

Desse modo, os conhecimentos precisam estar articulados entre as diversas áreas no que se refere aos conceitos, mas também ao encaminhamento da prática, a fim de que os licenciandos relacionem o que estão estudando com o espaço real, num enfoque que se apresente expressivo e contextualizado, conforme o que orientam os Parâmetros Curriculares Nacionais para o Ensino Médio (BRASIL, 2000; BRASIL, 2002c). É também nessa direção que argumentam os autores Oliveira, Tanzi-Neto (2016) e Morin (2014). Nesse sentido, a interdisciplinaridade pode ser colocada em prática por meio do desenvolvimento de projetos, com o objetivo de atingir metas coletivas, considerando o conjunto das grandes áreas do conhecimento.

\subsection{A VISÃo dOS DOCENTES FORMADORES A RESPEITO DO SABER O QUE ENSINAR NAS LICENCIATURAS EM CIÊNCIAS DA NATUREZA DO IFRO}

No que tange à visão dos trinta e três (33) DFs acerca da garantia do saber o que ensinar, a partir das diferentes disciplinas ofertadas ao longo dos cursos de licenciaturas, esses profissionais apresentam opiniões bastante distintas de um campus para outro e, até mesmo, do 
corpo docente de um mesmo curso. Opiniões estas, que apresenta-se a seguir com as devidas análises.

De modo a garantir o anonimato aos participantes, eles são aqui identificados com um número de 1 a 33 - DF 1, DF 2, DF 3, etc.

\subsubsection{DFs do CURSO de LiCenCiatura EM CiênCias Biológicas do IFRO do CAMPUS DE COLORADO DO OESTE}

Com relação aos resultados pertinentes ao saber o que ensinar, dos oito (08) DFs do campus de Colorado do Oeste, seis (06) (1, 2, 4, 5, 7 e 8) afirmaram que, sim, o curso contempla a garantia do saber o que ensinar, e dois (02) (3 e 6) responderam "em parte". Os DFs 1, 2, 4, 5,7 e 8 , que registraram sim, apresentam a justificativa para tal resposta afirmando que a “qualificação dos DFs, biblioteca, laboratórios, as metodologias, o empenho, dedicação, aulas práticas, aulas lúdicas e criativas fornecem uma base científica" aos alunos. Os DFs 3 e 6, que responderam "em parte", também se justificaram. O DF 3 afirmou que a "quantidade de horas para se trabalhar conteúdos específicos com a qualidade necessária para se formar um bom professor é insuficiente. Estamos formando professores com conteúdos específicos muito abaixo"; já o DF 6 afirmou que os "professores, na sua maioria, são bacharéis em suas áreas, trazendo conteúdo específico das disciplinas de caráter técnico."

Sendo assim, podemos afirmar que a maioria reconhece que os conhecimentos específicos, aliados aos recursos didáticos, favoreceram a garantia do saber o que ensinar. Observamos também que o entendimento dos DFs sobre os conhecimentos do saber que ensinar confere com o que está previsto na Resolução CNE/CP n. ${ }^{\circ}$ 2/2015, mais precisamente em seu artigo 12, inciso II (BRASIL, 2015), isto é, os compreendem como "Núcleo de aprofundamento e diversificação de estudos das áreas de atuação profissional, incluindo os conteúdos específicos [...]”.

A compreensão desses docentes acerca da importância dos recursos didáticos no processo de aquisição do saber o que ensinar condiz com a posição Matos et al. (2015), que relataram que há uma facilitação da apropriação e do entendimento de conceitos por meio em atividades com um enfoque prático, como as desenvolvidas por licenciandos do curso de Ciências Biológicas da Universidade Federal de Sergipe (UFS) e relatadas em monografias analisadas pelos autores. Tais atividades abordaram diferentes tópicos científicos, como os órgãos das plantas e os tipos de frutos, com base no uso de recursos como o jogo da memória e a preparação de uma salada de frutas. 
O olhar alicerçado na carga horária do conteúdo específico para os cursos de licenciatura em Ciências Biológicas, ora considerados, apresenta indicativos de uma formação em que o aspecto técnico do bacharelado tende a preponderar em relação à licenciatura. Krasilchik (2000) registrou, em seus estudos, a predominância da utilização de procedimentos metodológicos de ensino, por parte dos professores, ancorados em encadeamentos fixos e na cientificidade para identificar problemas e hipóteses e comprová-los por meio de experimentos que oportunizassem uma conclusão para geração de novos questionamentos.

\subsubsection{DFS DO CURSO DE LICENCIATURA EM QUÍMICA DO IFRO DO CAMPUS DE JI- PARANá}

Em relação ao campus de Ji-Paraná, dos nove (09) DFs, seis (06) (10, 11, 12, 13, 15 e 16) afirmaram que, sim, o curso contempla a garantia do saber o que ensinar, e três (03) (9, 14 e 17) responderam "em parte". Dos seis (06) que responderam sim, os DFs 15 e 16 não se justificaram, e quanto aos DFs 10,12, 13, a justificativa foi evasiva. O DF 11 justificou-se, dizendo que os "professores [do curso] são qualificados para a função". Os DFs 9, 14 e 17 registraram que a licenciatura contempla o referido saber apenas em parte e se justificaram dos seguintes modos: “[...]carência de profissional especializado em Libras [Língua Brasileira de Sinais] destinado à área de Química [...]" (DF 9); "Acredito que, por ser um curso novo, ainda há que se repensar algumas práticas para que não vire uma espécie de $5^{\circ}$ ou $4^{\circ}$ ano dos cursos técnicos e, sim, um curso pleno superior [...]” (DF 14); “[...] “Nem sempre a Instituição consegue acompanhar as mudanças que ocorrem no meio educacional" (DF 17).

Essas justificativas, embora não tenham respondido, de fato, ao questionamento, mostram aspectos relevantes para a nossa análise. Os docentes destacaram a necessidade de contratar um docente de Libras para o trabalho com os alunos surdos e de superar as características de um curso de nível médio. Mencionaram, ainda, que o IFRO não acompanha as mudanças educacionais vigentes, contudo não registraram em que sentido não ocorre o acompanhamento.

Tais aspectos são relevantes na medida em que podem ser incorporados às discussões dos DFs, seja no planejamento anual ou durante a reformulação dos PPC.

Sendo assim, esse curso de Licenciatura em Química aponta para a necessidade de uma discussão coletiva no sentido de realizar um alinhamento em relação à formação dos futuros professores, pois cinco (05) DFs não apresentaram justificativas para a afirmação de que o curso garante o saber o que ensinar. Além disso, duas justificativas são elas: DF 14 "Acredito que, 
por ser um curso novo, ainda há que se repensar algumas práticas para que não vire uma espécie de $5^{\circ}$ ou $4^{\circ}$ ano dos cursos técnicos e, sim, um curso pleno superior [...]" e DF 17 “[...] "Nem sempre a Instituição consegue acompanhar as mudanças que ocorrem no meio educacional" não estão diretamente vinculadas ao conhecimento discutido na pesquisa, que é o saber o que ensinar. Entretanto, para Veiga (2003, p. 275) o Projeto Pedagógico do Curso

\begin{abstract}
é um meio de engajamento coletivo para integrar ações dispersas, criar sinergias no sentido de buscar soluções alternativas para diferentes momentos do trabalho pedagógico - administrativo, desenvolver o sentimento de pertença, mobilizar os protagonistas para a explicitação de objetivos comuns definindo o norte das ações a serem desencadeadas, fortalecer a construção de uma coerência comum, mas indispensável para que a ação coletiva produza seus efeitos.
\end{abstract}

Portanto, a construção, a reformulação ou a discussão sobre a implementação de um PPC, pela equipe que leciona na Licenciatura em Química do campus de Ji-Paraná, possibilitaria maior segurança em relação as especificidades acadêmicas dos futuros professores daquela localidade. Além disto, quanto maior o grupo de docentes que atua ou atuou no curso pensando a proposta pedagógica, maior a possibilidade de se construir um efetivo processo de desenvolvimento do ensino e da aprendizagem.

\title{
4.2.3. DFs do CURSO de LiCEnCIATURA EM CiênCias BiológiCas do IFRO do CAMPUS DE ARIQUEMES
}

Dos sete (07) DFs do campus de Ariquemes, quatro (04) (DFs 19, 20, 21 e 24) afirmaram que, sim, o curso contempla a garantia do saber o que ensinar; três (03) (DFs 18, 22 e 23) responderam "em parte”. As justificativas destes três profissionais foram as seguintes: "Há, ainda, no âmbito do IFRO, a ideia de que o graduado em Ciências Biológicas será bacharel em Biologia, e não professor de Biologia [...]" (DF 18); "Nos primeiros três anos, o curso teve uma ênfase maior no bacharelado do que na licenciatura [...]" (DF 22); "O IFRO não contrata professores por área específica e, às vezes, os professores ministram aulas/matérias que não são da sua área de atuação" (DF 23). Os quatro docentes que afirmaram "sim" também se justificaram: "Ouço, durante as aulas, os comentários dos alunos de que o curso de Ciências Biológicas é rico em disciplinas específicas e que eles aprenderam muita coisa aqui que não tinham entendido no Ensino Médio (DF 19); “O curso aborda muito bem a parte técnica com a pedagógica, fazendo esse entrelaçamento das áreas" (DF 21); "O curso fornece os conteúdos suficientes para os alunos desenvolveram as suas futuras atividades docentes em mais ou $70 \%$ $[\ldots] "($ DF 24). 
Nas respostas dos DFs há uma predominância da ideia de que o curso possui características de bacharelado. Este aspecto, ao longo do processo de formação inicial de professores, tem sido questionado e, até mesmo, criticado na literatura por autores de diversas áreas do conhecimento, tais como Dinis-Pereira (1999), Pires (1999), Corôa (2006), Aranha; Souza (2013), dentre outros. Sendo assim, percebeu-se a necessidade de uma reflexão do grupo de DFs da referida licenciatura sobre essa característica em particular, no sentido de que isso venha a ser superado e incorporado ao PPC na perspectiva de formação docente.

\subsubsection{DFs do CURSO de LiCEnCIATURA EM FísiCA do IFRO do CAMPUS DE PORTO Velho Calama}

Dos nove (09) DFs do campus de Porto Velho Calama, sete (07) (25, 26, 27, 30, 31, 32 e 33) afirmaram que o saber o que ensinar está garantido no curso, e dois (02) DFs (28 e 29) responderam "apenas em parte". Dos sete (07) que responderam sim, dois (02) não se justificaram (DFs 25 e 26). O DF 27 justificou-se: "Eu priorizo os conteúdos que julgo necessários para uma boa base acadêmica". Já o DF 30 afirmou: "As bases científicas da ciência do curso são muito bem abordadas de maneira teórica e muitas vezes com auxílio experimental". Vejamos outras justificativas: "Os professores das disciplinas do eixo fundamental da licenciatura em Física possuem preparo intelectual, didático e pedagógico reconhecido [...], pois as disciplinas pedagógicas constantes do desenho curricular são especificadas para conduzirem o acadêmico ao nível necessário para a atuação em sala de aula" (DF 31); "bom planejamento" (DF 33). O DF 32 apresentou uma resposta evasiva.

Os DFs 28 e 29 justificaram-se, respectivamente, dos seguintes modos: "Faltam muitos conhecimentos prévios aos alunos, o que atrapalha na construção de novos conhecimentos"; "Muito mais que o conteúdo específico, o professor precisaria 'ensinar a ensinar' e essa falha acredito ser uma das nossas maiores fragilidades [...]”".

Em relação à Licenciatura em Física do campus de Porto Velho Calama, cabe mencionar que a decisão sobre o que se ensina está observada no PPC do curso e não é uma prerrogativa decisória única dos DFs. Os DFs entendem que o projeto que orienta o curso traz o que foi definido por uma coletividade, com base nas legislações e nas demandas contextualizadas da região. Observamos, ainda, uma preocupação com a ausência de determinados conhecimentos prévios por parte de alguns licenciandos desse campus, de acordo com o que citou o DF 28. Cabe salientar que tais licenciandos podem ter sido vítimas de um processo de escolarização cujos professores tenham se licenciado em instituições que não proporcionavam uma formação 
inicial de qualidade (GATTI; BARRETO, 2009), assim como podem ter estudado em escolas da Educação Básica com situações precárias, que comprometeram a qualidade do Ensino Fundamental e Médio (ZANON, 2008). De todo modo, o IFRO tem adotado algumas práticas que envolvem DFs e licenciandos dos últimos períodos da licenciatura em questão para minimizar tais lacunas.

Ainda, com relação a Licenciatura em Física, o DF 29 afirma que, muito mais do que o conteúdo específico, o professor formador precisaria "ensinar a ensinar", ou seja, possibilitar que os futuros professores saibam repassar os conhecimentos adquiridos, pois, quando o licenciando estiver atuando na Educação Básica, necessariamente, durante o processo de ensino, precisará do saber o que e o como ensinar (ANASTASIOU, 2007; GARCÍA, 1995; GAUTHIER et al., 1998; JIMÉNEZ; BRAVO, 2000; SHULMAN, 1986; TARDIF, 2003; BOLZAN, 2006). Já o DF 31 afirmou: “Os professores das disciplinas do eixo fundamental da Licenciatura em Física possuem preparo intelectual, didático e pedagógico reconhecido [...], pois as disciplinas pedagógicas constantes do desenho curricular são especificadas para conduzirem o acadêmico ao nível necessário para a atuação em sala de aula”. Observamos que o DF 31 compreende que o curso está cumprindo o seu papel na formação profissional para a docência, evitando, assim, que veicule uma concepção reducionista, que vem sendo debatida desde a década de 1980 por estudiosos como Krasilchik (1987), Delizoicov e Angotti (1997) e Carvalho e Gil-Pérez (2011), para citar alguns. Em razão desse processo de formação inicial de professores de Ciências da Natureza, ancorado na concepção de aprendizagem dos conteúdos específicos e reducionistas, o enfoque do ensino-aprendizagem estava na descoberta, com a qual - seguindo todas as fases do método científico - em tese, os alunos aprenderiam os conteúdos propostos.

\subsection{A ViSÃo dOS PES A RESPEITO dO SABER O QUE ENSINAR NAS LICENCIATURAS EM CiênCIAS dA NATUREZA do IFRO}

Foram cinco (05) os Professores Egressos (PEs) entrevistados, sendo um do campus de Colorado do Oeste, três (03) do campus Ji-Paraná e um (01) do campus Ariquemes. O PE do campus Porto Velho Calama optou por não participar da pesquisa, pois pretendia deixar a profissão assim que concluísse outro curso superior. Apresentando diferentes justificativas, todos os respondentes foram unânimes em afirmar que, sim, há uma garantia em relação ao saber o que ensinar a partir das diferentes disciplinas ofertadas ao longo das licenciaturas. Nas análises a seguir, de modo a garantir o anonimato a esses participantes da pesquisa, adotamos 
o mesmo procedimento referido para os DFs na subseção 4.2 e, Sendo assim, os PEs são aqui identificados com um número de 1 a 4 - PE 1, PE 2, PE 3 e PE 4.

O PE 1, licenciado em Ciências Biológicas pelo IFRO do campus de Colorado do Oeste, afirmou: “[...] o norte, a gente tem na faculdade, o resto você só vai acrescentar [...]”. Tal entendimento condiz com o que Zeichner (1993, p. 55) afirma, ao tratar da formação inicial de professores. Segundo o autor (1993, p. 55), a formação é "um processo que continua ao longo da carreira docente e que, não obstante a qualidade do que fizermos nos nossos programas de formação de professores, na melhor das hipóteses, só poderemos preparar os professores para começarem a ensinar".

Os PEs 2, 3 e 4, licenciados em Química pelo campus de Ji-Paraná, justificaram-se dos seguintes modos: “Deu pro básico, para o Ensino Médio. Com a formação da licenciatura, não ia passar aperto no Ensino Superior" (PE 2); “As aulas sempre foram bem estruturadas, poderiam ter sido melhores se houvesse à disposição todo o material de laboratório necessário às boas práticas, como livros e acesso à pesquisa" (PE 3); “Os professores da área específica ainda não estavam engrenados no ensinar os conteúdos. Tinham os conhecimentos, mas não a convicção do que deveriam fazer para ensinar de maneira clara para serem entendidos pelo aluno" (PE 4).

Os três PEs da Licenciatura em Química apresentaram respostas distintas, mas que corroboraram com os conhecimentos relativos ao saber o que ensinar, na medida em que tais falas remetem ao fato de que a qualificação do DF, a biblioteca, os laboratórios, as metodologias, as aulas práticas e a base científica são determinantes para a aprendizagem dos alunos. Isto condiz com os estudos de Candau (1982), Feldens (1984), Pérez-Gómez (1997), Diniz-Pereira (1999), Contreras (2002) e Gatti e Nunes (2009), ao tratarem da priorização dos conhecimentos técnicos e científicos. Também condiz com a pesquisa de Matos et al. (2015), principalmente em relação à contribuição dos recursos didáticos para o processo de ensino e de aprendizagem de conteúdos pertinentes à área de Biologia.

O PE 5, licenciado em Ciências Biológicas pelo campus Ariquemes, justificou-se afirmando que "A área específica foi muito bem abordada". A justificativa desse PE aludiu à ideia de que os conteúdos disciplinares na licenciatura em questão se apresentam como significativos para o desenvolvimento do curso na perspectiva dos futuros professores.

O argumento do PE 5 está de acordo com a afirmação de Mizukami et al. (2010, p. 19): 
suficiente para converter uma pessoa em professor. Ou seja, conhecer mais sobre uma dada área não implica ensinar melhor. Por outro lado, professores com insuficiente domínio de conteúdo específico com certeza ensinam, mas precariamente, quando não ensinam errado. A ausência de profunda compreensão sobre certos aspectos de conteúdo específico de uma área de conhecimento pode impedir um bom ensino.

Assim, pode-se afirmar no que tange ao conhecimento específico, que a compreensão do Professor Egresso 5, corrobora com as discussões acadêmicas científicas vinculadas a saberes das matérias.

\section{CONSIDERAÇÕES FINAIS}

Nas licenciaturas em Ciências da Natureza, o saber o que ensinar precisa vincular-se às práticas pedagógicas desenvolvidas nos ambientes escolares e estar intensamente interligado às aspirações sociais e às demandas decorrentes da complexidade do espaço educativo formal, que é a escola. De fato, esse espaço se constitui uma ferramenta importante para a formação de um professor e, simultaneamente, para o êxito do desenvolvimento do aluno, ao longo da sua escolarização.

Neste sentido, a pesquisa realizada a partir dos PPCs das licenciaturas em Ciências Biológicas, Química e Física do IFRO, constatamos uma disparidade no que tange ao número de disciplinas pertinentes ao saber o que ensinar nesses cursos. Também comprovou-se ausência de disciplinas cujo enfoque assegurassem conhecimentos da região - neste caso, da Amazônia.

Com relação à visão dos DFs quanto à garantia do saber o que ensinar na Licenciatura em Ciências Biológicas do campus de Colorado do Oeste, os participantes da pesquisa apresentaram a compreensão dos conhecimentos desse saber, conforme estabelecidos na Resolução CNE/CP n. ${ }^{\circ}$ 2/2015 (BRASIL, 2015); entretanto, mesmo se tratando de um curso de formação inicial de professores, ainda, verificou-se a presença de um olhar ancorado na perspectiva do bacharelado.

Quanto ao ponto de vista dos DFs sobre a segurança do saber o que ensinar na Licenciatura em Química do IFRO do campus Ji-Paraná, os profissionais ressaltaram a necessidade de uma discussão coletiva para alinhar a compreensão da formação na licenciatura. Em prol do fortalecimento do curso de formação inicial de professores de Química, são necessários engajamento e protagonismo dos envolvidos.

$\mathrm{Na}$ visão dos DFs a respeito do saber o que ensinar na Licenciatura em Ciências Biológicas do IFRO, campus Ariquemes, predominaram menções a aspectos relacionados ao 
bacharelado, que não comungam diretamente com os cursos de formação inicial de professores, pois o enfoque é distinto, em razão das funções do próprio profissional.

Já a visão dos DFs da Licenciatura em Física do IFRO do campus de Porto Velho Calama, em relação ao saber o que ensinar, três opiniões distintas foram identificadas. A primeira é a de que as disciplinas são desenvolvidas com base na priorização de conteúdos julgados como imprescindíveis para a boa formação acadêmica; a segunda alega que faltam aos alunos conhecimentos prévios de determinados conteúdos; e a terceira defende que, além de saber o que ensinar, o professor também precisa se apropriar do saber como ensinar. Entendemos que todas essas opiniões são indicativas de um processo de rediscussão da formação inicial de professores. A terceira, um grupo de DFs com domínio dos distintos contextos da licenciatura em questão terá maior propriedade para promover as mudanças que se fizerem necessárias visando à implementação de um curso que atenda às necessidades educativas e formativas da comunidade em questão.

Em síntese, nos cursos de licenciaturas em Ciências da Natureza analisados, embora predomine, entre os DFs (24 de 33 profissionais), a visão de que o IFRO garante os conhecimentos do saber o que ensinar, nas justificativas foram apontadas algumas lacunas pertinentes a matéria. Isso requer debates e ações coletivas, de modo a ultrapassar os aspectos negativos elencados.

Os cinco (5) PEs dos cursos de licenciaturas em Ciências Biológicas, Química e Física foram unânimes em afirmar que a formação inicial de professores, ofertada pelo IFRO, garante o saber o que ensinar. Eles reconhecem que as aulas foram bem conduzidas, e os conteúdos disciplinares, bem escolhidos. Além disso, mesmo sendo os pioneiros nas licenciaturas da instituição, os egressos entrevistados mencionaram que tiveram laboratórios à disposição, desenvolveram atividades práticas e contaram com um bom acervo bibliográfico para acesso a pesquisas.

\section{REFERÊNCIAS}

ANASTASIOU, Léa das Graças Camargo. Propostas curriculares em questão: saberes docentes e trajetórias de formação. In: CUNHA, Maria Isabel da (Org.). Reflexões e Práticas em Pedagogia Universitária. Campinas, SP: Papirus, 2007.

ARANHA, Antônia Vitória Soares; SOUZA, João Valdir Alves de. As licenciaturas na atualidade: nova crise? Educar em Revista, Curitiba, Brasil, n. 50, p. 69-86, out./dez. 2013, Editora UFPR. Disponível em: https://bit.ly/2D40vDk. Acesso em: 17 ago. 2018. 
BARBOSA, Edson Pereira. Leituras sobre o processo de implantação de uma licenciatura em Ciências Naturais e Matemática por área de conhecimento. 2012. $311 \mathrm{f}$. Tese (Doutorado em Educação Matemática) - Instituto de Geociências e Ciências Exatas, Universidade Estadual Paulista, Rio Claro, 2012. Disponível em:

https://repositorio.unesp.br/bitstream/handle/11449/102116/barbosa_ep_dr_rcla.pdf?sequence =1\&isAllowed=y. Acesso em: 11 de jun. 2019.

BOLZAN, Doris Pires Vargas. Verbetes. In: MOROSINI, Marília Costa. (Org.).

Enciclopédia de Pedagogia Universitária. Glossário vol. 2. Brasília: Instituto Nacional de Estudos e Pesquisas Educacionais Anísio Teixeira, 2006. Disponível em:

https://bit.ly/35v7otB. Acesso em: 11 jun. 2019.

BORGES, Cecília Maria Ferreira. O professor da Educação Básica e seus saberes profissionais. 1. ed. Araraquara: JM, 2004.

BRASIL. Lei n..$^{\circ}$ 9.394/1996, de 20 de dezembro de 1996. Estabelece as diretrizes e bases da educação nacional. Diário Oficial [da] República Federativa do Brasil, Poder Executivo, Brasília, DF, 23 dez. 1993. Disponível em: https://bit.ly/2OtaozH. Acesso em: 11 jun. 2019.

BRASIL. Ministério da Educação. Parâmetros Curriculares Nacionais Ensino Médio: Parte III - Ciências da Natureza, Matemática e suas Tecnologias. Brasília, 2000. Disponível em: http://tiny.cc/9z5kgz. Acesso em: 14 jun. 2019.

BRASIL. Ministério da Educação. Conselho Nacional de Educação. Parecer n. ${ }^{0}$ 1.304/2001. Diretrizes Nacionais Curriculares para os Cursos de Física. Diário Oficial [da] República Federativa do Brasil, Poder Executivo, Brasília, DF, 07 dez. 2001a, seção 1, p. Disponível em: http://tiny.cc/7z8kgz. Acesso em: 11 jun. 2019.

BRASIL. Ministério da Educação. Conselho Nacional de Educação. Parecer n. ${ }^{\circ}$ 1.301/2001. Diretrizes Curriculares Nacionais para os Cursos de Ciências Biológicas. Diário Oficial [da] República Federativa do Brasil, Poder Executivo, Brasília, DF, 07 dez. 2001b, seção 1, p. Disponível em: http://tiny.cc/7z8kgz. Acesso em: 11 jun. 2019.

BRASIL. Ministério da Educação. Conselho Nacional de Educação. Parecer n. ${ }^{\circ}$ 1.303/2001. Diretrizes Curriculares Nacionais para os Cursos de Química. Diário Oficial [da] República Federativa do Brasil, Poder Executivo, Brasília, DF, 07 dez. 2001c, seção 1, p. Disponível em: http://tiny.cc/038kgz. Acesso em: 11 jun. 2019.

BRASIL. Ministério da Educação. Conselho Nacional de Educação. Resolução CNE/CP n. ${ }^{\circ}$ 1, de 18 de fevereiro de 2002. Institui Diretrizes Curriculares Nacionais para a Formação de Professores da Educação Básica, em nível superior, curso de licenciatura, de graduação plena. Diário Oficial [da] República Federativa do Brasil, Poder Executivo, Brasília, DF, 09 abr. 2002a, seção 1, p. 31. Disponível em: http://tiny.cc/0y8kgz. Acesso em: 11 jun. 2019.

BRASIL. Ministério da Educação. Conselho Nacional de Educação. Resolução CNE/CP n. ${ }^{\circ}$ 2, de 19 de fevereiro de 2002. Institui a duração e a carga horária dos cursos de licenciatura, de graduação plena, de formação de professores da Educação Básica em nível superior. Diário Oficial [da] República Federativa do Brasil, Poder Executivo, Brasília, DF, 04 mar. 2002b, seção 1, p. 9. Disponível em: http://tiny.cc/9z5kgz. Acesso em: 14 jun. 2019. 
BRASIL. Ministério da Educação. PCNEM + Ensino Médio: Orientações Educacionais Complementares aos Parâmetros Curriculares Nacionais. Ciências da Natureza, Matemática e suas Tecnologias. Brasília, 2002c. Disponível em: https://bit.ly/2KGTht7. Acesso em: 14 jun. 2019.

BRASIL. Ministério da Educação. Conselho Nacional de Educação. Resolução CNE n. ${ }^{\circ}$, de 1. ${ }^{\circ}$ de julho de 2015. Define as Diretrizes Curriculares Nacionais para a formação inicial em nível superior (cursos de licenciatura, cursos de formação pedagógica para graduados e cursos de segunda licenciatura) e para a formação continuada. Diário Oficial [da] República Federativa do Brasil, Poder Executivo, Brasília, DF, 03 jul. 2015, seção 1, p. 28. Disponível em: http://tiny.cc/wz6kgz. Acesso em: 12 jun. 2019.

BUCHMANN, Margret. The priority of Knowledge and understanding in teaching. In: KATZ, Lilian; RATHS, Jonas. (Eds.). Advances in Teacher Education (vol. 29-50).

Norwood: Ablex. 1984. Disponível em: https://shorturl.at/knoL3. Acesso em: 11 jun. 2019.

CANDAU, Vera Maria Ferrão. A formação de educadores: uma perspectiva multidimensional. Em aberto. Brasília, 1 (8): 19-21, ago. 1982.

CARVALHO, Anna Maria Pessoa de; GIL-PÉREZ, Daniel. Formação de professores de ciências: tendências e inovações. 10. ed. São Paulo: Cortez, 2011.

CELLARD, André. A análise documental. In: POUPART, Jean et al. A pesquisa qualitativa: enfoques epistemológicos e metodológicos. Petrópolis: Vozes, 2008.

CONTRERAS, José. Autonomia de professores. 2. ed. São Paulo: Cortez, 2002.

CORÔA, Renata Paixão. Saberes construídos pelos professores de matemática em sua prática docente na educação de jovens e adultos. 2006. 110 fls. Dissertação (Mestrado em Educação e Ciências Matemáticas) - Programa de Pós-Graduação em Educação em Ciências e Matemáticas, Universidade Federal do Pará, Belém, 2006. Disponível em: http://repositorio.ufpa.br/jspui/bitstream/2011/1784/1/Dissertacao_SaberesProfessoresMatem atica.pdf. Acesso em: 11 de jun. 2019.

DELIZOICOV, Demétrio; ANGOTTI, José André. Metodologia do Ensino de Ciências. São Paulo: Cortez, 1997.

DINIZ-PEREIRA, Júlio Emílio. As licenciaturas e as novas políticas educacionais para a formação docente. Educação \& Sociedade, ano XX, n. ${ }^{\circ}$ 68, dezembro, 1999. Disponível em: http://www.scielo.br/pdf/es/v20n68/a06v2068.pdf. Acesso em: 13 jun. 2019.

FAZENDA, Ivani Catarina Arantes. Interdisciplinaridade um projeto em parceria. São Paulo: Loyola, 2017.

FELDENS, Maria das Graças Furtado. Educação de professores: tendências, questões e prioridades. Tecnologia Educacional, Rio de Janeiro, 13(61):16-26, nov./dez. 1984.

FREIRE, Paulo. Pedagogia da autonomia: saberes necessários à prática educativa. São Paulo: Paz e Terra, 1996. 
GARCÍA, Carlos Marcelo. Formación del professorado para el cambio educativo. 2. ed. Barcelona: Espanã. Editora EUB. 1995.

GATTI, Bernadete Angelina; BARRETO Elba Siqueira de Sá. Professores do Brasil: impasses e desafios. Brasília: UNESCO, 2009.

GATTI, Bernadete Angelina; NUNES Marina Muniz Rossa. Formação de professores para o ensino fundamental: estudo de currículos das licenciaturas em pedagogia, língua portuguesa, matemática e ciências biológicas. São Paulo: FCC/DPE, 2009. Disponível em: http://tiny.cc/gsllgz. Acesso em: 12 jun. 2019.

GAUTHIER, Clermont et al. Por uma teoria da Pedagogia. Ijuí: Unijuí, 1998.

INSTITUTO FEDERAL DE EDUCAÇÃO, CIÊNCIA E TECNOLOGIA DE RONDÔNIA. Resolução n. ${ }^{\circ}$ 6, de 14 de dezembro de 2009. Dispõe sobre o Projeto Pedagógico do Curso de Licenciatura em Química, do Instituto Federal de Educação, Ciência e Tecnologia de Rondônia - Campus Ji-Paraná. Aprovado Ad referendum. Coordenação de Licenciatura. Colorado do Oeste.

INSTITUTO FEDERAL DE EDUCAÇÃO, CIÊNCIA E TECNOLOGIA DE RONDÔNIA. Resolução n. ${ }^{\circ}$ 5/CONSUP/IFRO, de 12 de março de 2012a. Dispõe sobre o Projeto Pedagógico do Curso de Licenciatura em Física, do Instituto Federal de Educação, Ciência e Tecnologia de Rondônia - Campus Porto Velho Calama. Disponível em: https://bit.ly/2CTywWO. Acesso em: 13 jun. 2019.

INSTITUTO FEDERAL DE EDUCAÇÃO, CIÊNCIA E TECNOLOGIA DE RONDÔNIA. Resolução n. ${ }^{\circ}$ 7/CONSUP/IFRO, de 12 de março de 2012b. Dispõe sobre o Projeto Pedagógico do Curso de Licenciatura em Ciências Biológicas, do Instituto Federal de Educação, Ciência e Tecnologia de Rondônia - Campus Ariquemes. Disponível em: https://bit.ly/2D3DO1S. Acesso em: 13 jun. 2019.

INSTITUTO FEDERAL DE EDUCAÇÃO, CIÊNCIA E TECNOLOGIA DE RONDÔNIA. Resolução n. ${ }^{\circ}$ 8/CONSUP/IFRO, de 12 de março de 2012c. Dispõe sobre o Projeto Pedagógico do Curso de Licenciatura em Ciências Biológicas, do Instituto Federal de Educação, Ciência e Tecnologia de Rondônia - Campus Colorado do Oeste. Disponível em: https://bit.ly/35iUzCk. Acesso em: 12 jun. 2019.

JAPIASSÚ, Hilton. Interdisciplinaridade e patologia do saber. Rio de Janeiro: Imago, 1976.

JIMÉNEZ, Vicente. Mellado; BRAVO, Teodoro. González. La formación inicial del professorado de ciências. In: PERALES, J.; CANÃL, P. Didáctica del las ciencias experimentales. Alcoy: Marfil, 2000.

KRASILCHIK, Myriam. O professor e o currículo das ciências. São Paulo: EPU/EDUSP, 1987.

KRASILCHIK, Myriam. Reformas e realidade: o caso do ensino das ciências. São Paulo em Perspectiva, v. 14, n. 1, 2000. 
MATOS, Gilda Maria Amarante et al. Recursos didáticos para o ensino de botânica: uma avaliação das produções de estudantes em Universidade Sergipana. HOLOS, Ano 31, v. 5, p. 213-230, 2015. Disponível em: https://bit.ly/34d4qtu. Acesso em: 18 jul. 2018.

MINAYO, Maria Cecília de Souza (Org.). Pesquisa Social. Teoria, método e criatividade. 18 ed. Petrópolis: Vozes, 2001.

MIZUKAMI, Maria da Graça Nicoletti et al. Escola e aprendizagem da docência: processos de investigação e formação. São Carlos: EdUFSCAR, 2002.

MIZUKAMI, Maria da Graça Nicoletti et al. Escola e aprendizagem da docência: processos de investigação e formação. 2. ed. São Carlos: EDUFSCar, 2010.

MORIN, Edgar. A cabeça bem-feita: repensar a reforma, reformar o pensamento. Tradução: Eloá Jacobina. 21. ed. Rio de Janeiro: Bertrand Brasil, 2014.

NIZA, Sergio. Entrevista com o Dr. Sergio Niza para a revista Camine: depoimento. 2 vídeos (13' 55') Entrevistadores: Célia David e Ricardo Ribeiro. Universidade Estadual Paulista, Faculdade de Ciências Humanas e Sociais, Campus de Franca. 13 ago. 2012. Disponível em: https://bit.ly/2QDdbc1. Acesso em: 14 jun. 2019.

OLIVEIRA, Grassinete Carioca de Albuquerque; TANZI-NETO, Adolfo. Inter, trans, pluri e multi (disciplinaridade): Como esses conceitos contribuem para a sala de aula do professor de língua nacional?. Simpósio Linguagens e Identidades da/na Amazônia Sul-Ocidental. Anais [...]. Universidade Federal do Acre, 2016. Disponível em: http://tiny.cc/limlgz. Acesso em: 15 jun. 2019.

PENHA, Maranei Rohers. A Implantação e Implementação de Licenciaturas de Ciências da Natureza no Instituto Federal de Educação, Ciências e Tecnologia de Rondônia IFRO. 2018. 307 f. Tese (Doutorado em Educação em Ciências e Matemática) Universidade Federal de Mato Grosso, Rede Amazônica de Educação em Ciências e Matemática, Programa de Pós- Graduação em Educação em Ciências e Matemática, Cuiabá, 2019. Disponível em: https://www1.ufmt.br/ufmt/unidade/userfiles/publicacoes/677a88efe 7dc5497dc9852dbfd2dffb f.pdf. Acesso em 02-02-2020.

PÉREZ GÓMEZ, Angel. O pensamento prático do professor: A formação do professor como profissional reflexivo. In: NÓVOA, Antonio (Org.). Os professores e a sua formação. 3. ed. Lisboa: Dom Quixote, 1997.

PIRES, Célia Maria Carolino. Novos desafios para os cursos de Licenciatura em Matemática. Campinas-SP: Mimeo, 1999.

SCHÖN, Donald. The reflective practitioner. New York: Basic Books, 1983.

SELLTIZ, Claire et al. Métodos de pesquisa nas relações sociais. São Paulo: E.P.U., 2007.

SHULMAN, Lee. Those who understand: knowledge growth in teaching. Educational Researcher, v. 15, n. 2, fev. 1986, p. 4-14. Disponível em: http://tiny.cc/wjmlgz. Acesso em: 10 out. 2019.

TARDIF, Maurice. Saberes docentes e formação profissional. Petrópolis (RJ): Vozes, 2003. 
VEIGA, Ilma Passos Alencastro. Inovações e Projeto Político-Pedagógico: uma relação regulatória ou emancipatória? Cad. Cedes, Campinas, v. 23, n. 61, p. 267-281, dezembro 2003. Disponível em: http://www.scielo.br/pdf/ccedes/v23n61/a02v2361.pdf. Acesso em: 15 jun. 2019.

ZANON, Lenir Basso et al. Recontextualização pedagógica de contextos/conteúdo de ciências em uma prática interdisciplinar e contextualizada no Ensino Médio. In: GAGLIAZZI, Maria do Carmo et al. (Org.). Aprender em Rede na Educação em Ciências. Ijuí: Unijuí, 2008.

ZEICHNER, Kenneth M. Formação reflexiva de professores: ideias e práticas. Lisboa: Educa, 1993.

Recebido em: 17 de dezembro de 2019.

Aprovado em: 06 de abril de 2020. 